Experienced endoscopy nurse used to visit patients a day before the preassessed list to provide standard consent documentation, discuss preparation requirement (with patients, nursing and medical staff), ensure proper prescription of bowel preparation and to assess patient's fitness for procedure and capacity for consent. Gastroenterology SPR was available to address any concerns regarding fitness for procedure and capacity to give consent.

Results 100 cases were scheduled in preassessed lists of which 85 were performed while 15 were delayed ( $7 / 15$ were cancelled due to deterioration in patient's condition and 8 due to other reasons including withdrawal of consent, deranged coagulation and inability to take full bowel preparation). On un-preassessed list, 23/71 were delayed (32\%) while 48 procedures were performed (68\%). This was found to be statistically significant ( $p=0.0089$, Fisher's exact test).

14 patients were cancelled during preassessment and slots were allocated to other patients which helped in better utilisation of available resources, reduction of inpatient waiting list and length of hospital stay.

Conclusion The authors concluded that preassessment by endoscopy nurse resulted in better organisation of list and utilisation of available resources. It was also cost-effective by reducing cancellations and impact on inpatient stay. It helped in better patient information and less anxiety resulting in more relaxed patient, well-tolerated procedure and reduction in sedation use. On basis of above results, the authors recommend preassessment of all endoscopy lists to help in meeting the increased demand on service by improved organisation.

Competing interests None.

Keywords endoscopy, preassessment.

\section{PTH-132 \\ ROLE OF ENDOSCOPY NURSE PREASSESSMENT IN THE RUNNING OF INPATIENT ENDOSCOPY LIST: HOW EFFECTIVE IT IS?}

doi:10.1136/gut.2011.239301.533

S D Jafri, 1," N Faulkner, ${ }^{1}$ K Mason, ${ }^{1}$ D Fraser, ${ }^{1}$ P M Neville1 ${ }^{1}$ Gastroenterology, Nevill Hall Hospital, Abergavenny, UK

Introduction The procedure load of endoscopic procedures are ever increasing and proper management of the endoscopy unit with appropriate prioritisation is needed for smooth running of the service. Endoscopy team has noted on many occasion that inpatient procedures were cancelled at short notice or patient turned up for the procedure with incorrect and inadequate preparation, not being consented or procedure was found inappropriate.

This study was aimed to look for efficacy of endoscopy nurse preassessment in smooth running of the list by addressing issues of inadequate bowel preparation, consent and appropriateness of the procedure thus reducing cancellations.

Methods This project was conducted at Nevill Hall Hospital from November 2009 till March 2010 and was designed as PDSA (Plan;Do;See;Act) cycle. Two specific weekly inpatient lists (Wednesday and Friday) with two consultants were selected. For first 2 months, Friday list was preassessed and Wednesday list was left un-preassessed while for next 3 months, this was reversed. Each list acted as a control for the other. 